\title{
A Deep Learning Line to Assess Patient's Lung Cancer Stages
}

\author{
André Dias (1D), João Fernandes (D), Rui Monteiro (D), Joana Machado (iD,

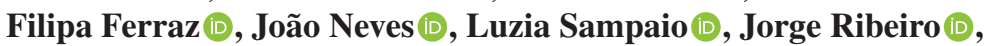 \\ Henrique Vicente $\mathbb{D}$, Victor Alves (i) and José Neves (i)
}

\begin{abstract}
Our goal is to pursue a vision of developing and maintaining a comprehensive and integrated computer model to help physicians plan the most appropriate treatment and anticipate a patient's prospects for the extent of cancer. For example, cancer can be treated at an early stage by surgery or radiation, while chemotherapy may be the care for more advanced stages. In fact, early detection of this type of cancer facilitates its treatment and may rise the patients' prospect of a continued existence. Thus, a formal view of an intelligent system for performing cancer feature extraction and analysis in order to establish the bases that will help physicians plan treatment and predict patient's prognosis is presented. It is based on the Logic Programming Language and draws a line between Deep Learning and Knowledge Representation and Reasoning, and is supported by a Case Based attitude to computing. In fact, despite the fact that each patient's condition is different, treating cancer at the same stage is often similar.
\end{abstract}

\footnotetext{
A. Dias $\cdot$ J. Fernandes $\cdot$ R. Monteiro $\cdot$ F. Ferraz

Departamento de Informática, Escola de Engenharia, Universidade Do Minho, Braga, Portugal

e-mail: andrepldias@hotmail.com

J. Fernandes

e-mail: joaovieirafernandes@hotmail.com

R. Monteiro

e-mail: ruifgmonteiro@gmail.com

F. Ferraz

e-mail: filipatferraz@gmail.com

J. Machado

Farmácia de Lamaçães, Braga, Portugal

e-mail: joana.mmachado@gmail.com

F. Ferraz $\cdot$ H. Vicente $(\varangle) \cdot$ V. Alves $\cdot$ J. Neves $(\varangle)$

Centro Algoritmi, Universidade Do Minho, Braga, Portugal

e-mail: hvicente@uevora.pt

J. Neves

e-mail: jneves@di.uminho.pt

(C) Springer Nature Singapore Pte Ltd. 2019

X.-S. Yang et al. (eds.), Third International Congress on Information

and Communication Technology, Advances in Intelligent Systems

and Computing 797, https://doi.org/10.1007/978-981-13-1165-9_55

9 pp.
} 
Keywords Logic programming $\cdot$ Knowledge representation and reasoning Intelligent systems $\cdot$ Case-based reasoning $\cdot$ Lung cancer $\cdot$ Computed Tomography

V. Alves

e-mail: valves@di.uminho.pt

J. Neves

Mediclinic Arabian Ranches, PO Box 282602, Dubai, United Arab Emirates

e-mail: joaocpneves@gmail.com

L. Sampaio

Dubai Healthcare City, PO Box 118855, Dubai, UAE

e-mail: luzia.sampaio@dbaj.ae

J. Ribeiro

Escola Superior de Tecnologia E Gestão, ARC4DigiT_-Applied Research Center for Digital

Transformation Instituto Politécnico de Viana Do Castelo, Viana Do Castelo, Portugal e-mail: jribeiro@estg.ipvc.pt

H. Vicente

Departamento de Química, Escola de Ciências E Tecnologia, Centro de Química de Évora, Universidade de Évora, Évora, Portugal 